\title{
ANALISIS PENINGKATAN KINERJA KARYAWAN DI UP PTSP KECAMATAN MAKASAR DENGAN METODE STRUCTURAL EQUATION MODELLING (SEM)
}

\author{
Arif Rahman ${ }^{1}$, Surya Perdana ${ }^{2}$ \\ Program Studi Teknik Industri, Universitas Indraprasta PGRI \\ arif.rahman0876@gmail.com ${ }^{1}$, suryaperdana.st.mm@gmail.com ${ }^{2}$
}

Submitted May 7, 2020; Revised June 27, 2020; Accepted July 2, 2020

\begin{abstract}
Abstrak
Penurunan kinerja karyawan di UP PTSP Kecamatan Makasar ditandai dengan tingkat efisiensi waktu pelayanan yang menurun di bidang perizinan KRK dan IMB. Selain itu penyebab menurunnya kinerja karyawan dikarenakan perilaku karyawan yang suka menunda pekerjaan dan datang terlambat kerja dengan sengaja, dan juga karyawan kurang memiliki tekad semangat yang tinggi pada saat bekerja. Pencapaian tugas karyawan UP PTSP Kecamatan Makasar tidak sesuai dengan standar waktu yang telah ditentukan. Tujuan penelitian adalah untuk mengetahui pengaruh lingkungan kerja dan beban kerja terhadap kinerja karyawan UP PTSP Kecamatan Makasar serta mengetahui faktorfaktor yang harus di prioritaskan untuk menjadi lebih baik. Data yang digunakan untuk penelitian adalah data kuesioner yang diolah dengan metode Structural Equation Modelling (SEM). Penelitian ini menganalisis faktor-faktor lingkungan kerja dan beban kerja menggunakan Structural Equation Modelling (SEM) dengan aplikasi AMOS. Berdasarkan nilai output regression weights SEM menyatakan bahwa tidak ada pengaruh yang signifikan antara lingkungan kerja terhadap kinerja karyawan. Sedangkan ada pengaruh yang signifikan antara beban kerja terhadap kinerja karyawan. Prioritas utama dalam meningkatkan kinerja karyawan melalui lingkungan kerja yaitu dengan kebersihan di tempat kerja. Prioritas utama dalam meningkatkan kinerja karyawan melalui beban kerja yang lebih baik yaitu dengan kondisi pekerjaan di tempat kerja.
\end{abstract}

Kata Kunci: Lingkungan Kerja, Beban Kerja, Kinerja Karyawan, Structural Equation Modelling.

\begin{abstract}
The decline in employee performance at UP PTSP Makasar District is characterized by a decreased level of service time efficiency in the area of KRK and IMB licensing. In addition, the cause of the decline in employee performance is due to the behavior of employees who like to postpone work and come late to work intentionally, and also employees lack the determination of high morale at work. The achievement of the duties of UP PTSP employees in Makasar Sub-District was not in accordance with the determined time standard. The purpose of this study was to determine the effect of the work environment and workload on the performance of UP PTSP Makasar District employees and to know the factors that had to be prioritized to become better. The data used for research is questionnaire data which is processed by the Structural Equation Modeling (SEM) method. This study analyzes the factors of work environment and workload using Structural Equation Modeling (SEM) with AMOS applications. Based on SEM output regression weights value states that there is no significant effect between work environment on employee performance. While there is a significant effect between workload on employee performance. The main priority in improving employee performance through the work environment is cleanliness in the workplace. The main priority in improving employee performance through better workloads is with work conditions at the workplace.
\end{abstract}

Keywords: Work Environment, Workload, Employee Performance, Structural Equation Modeling.

\section{PENDAHULUAN}

Pelayanan prima merupakan sesuatu yang diharapkan oleh masyarakat dalam melakukan kegiatan administrasi baik perizinan maupun non-perizinan. Di Indonesia khususnya Propinsi DKI Jakarta, 
pelayanan prima masih menjadi suatu kendala tersendiri terutama bagi masyarakat yang sedang mengurus perizinan dan non perizinan pada suatu instansi. Sehingga pemerintah pada saat itu memikirkan solusi untuk mempermudah perizinan dengan membentuk Dinas Penanaman Modal dan Pelayanan Terpadu Satu Pintu (DPMPTSP). Penelitian ini dilakukan di Unit Pelayanan Terpadu Satu Pintu (UP PTSP) Kecamatan Makasar yang berada di bawah naungan Dinas Penanaman Modal dan Pelayanan Terpadu Satu Pintu (DPMPTSP) Provinsi DKI Jakarta. Unit Pelayanan Terpadu Satu Pintu (UP PTSP) Kecamatan Makasar sebagai salah satu unit pelaksana yang bertugas dalam memberikan pelayanan perizinan dan non-perizinan dituntut untuk memberikan pelayanan prima sesuai dengan standar yang ditetapkan. Sehingga pelayanan mampu menjangkau seluruh lapisan masyarakat yang berdampak menurunnya tingkat pengaduan masyarakat dan mencegah terjadinya keterlambatan pengurusan perizinan dan non-perizinan.

Faktor yang menyebabkan pelayanan prima sulit terwujud yaitu disebabkan oleh penurunan kinerja karyawan. Penurunan kinerja karyawan di Unit Pelayanan Terpadu Satu Pintu (UP PTSP) Kecamatan Makasar ditandai dengan adanya tingkat efisiensi waktu pelayanan yang semakin menurun setiap bulannya di bidang perizinan Ketetapan Rencana Kota (KRK) dan Izin Mendirikan Bangunan (IMB). Selain itu pencapaian tugas karyawan Unit Pelayanan Terpadu Satu Pintu (UP PTSP) Kecamatan Makasar sering kali tidak sesuai dengan standar waktu yang telah ditentukan untuk menyelesaikan pekerjaan. Berdasarkan pengalaman di lapangan masalah yang berpengaruh terhadap kinerja karyawan pada Unit Pelayanan Terpadu Satu Pintu (UP PTSP) Kecamatan Makasar adalah beban kerja dan lingkungan kerja.
Kondisi lingkungan kerja yang tidak sesuai akan menyebabkan karyawan kurang nyamanan dalam bekerja dan berdampak kepada kurang disiplinnya karyawan, seperti terlambat masuk kerja, sering tidak ada di tempat saat jam kerja dan sering menunda pekerjaan. Dari kondisi tersebut terlihat bahwa semangat karyawan dalam melaksanakan tanggung jawabnya sebagai karyawan masih kurang dan perlu motivasi lebih agar produktifitas karyawan tidak terganggu yang akan berakibat kepada penurunan kepuasan masyarakat.

Permasalahan yang dihadapi manajemen dalam upaya mencapai tujuan perusahaan selain pada bahan mentah, peralatan kerja, mesin produksi, modal dan lingkungan kerja, yaitu pada pengelolaan Sumber Daya Manusia (SDM) dan faktor produksi lainnya [1]. Untuk meningkatkan kinerja organisasi melalui kinerja karyawan terdapat beberapa faktor yang harus diperhatikan, diantaranya: budaya organisasi, motivasi karyawan, dan komitmen karyawan [2]. Manajemen Sumber Daya Manusia (MSDM) menjadi hal penting dikarenakan dengan mengelola Sumber Daya Manusia (SDM) secara optimal akan menghasilkan Sumber Daya Manusia (SDM) yang handal, profesional dan memiliki loyalitas tinggi [3].

Kinerja merupakan hasil kerja yang dicapai karyawan selama melaksanakan tugasnya yang berdasarkan kecakapan, pengalaman dan kesungguhan karyawan pada ketepatan waktu penyelesaian pekerjaan [4]. Indikator kinerja yaitu terdiri dari: kualitas, kuantitas, ketepatan waktu, efisiensi, dan standar prosedur kerja [5]. Kualitas kehidupan kerja dalam organisasi sangat berpengaruh terhadap kinerja karyawan. Di mana kualitas kehidupan kerja dapat mempengaruhi kedisiplinan karyawan yang berdampak kepada kinerja organisasi [6]. Lingkungan kerja juga dapat mempengaruhi kinerja karyawan. Di mana lingkungan kerja yang dimaksud yaitu 
segala sesuatu yang berada di sekitar karyawan. Faktor pada lingkungan kerja dapat berupa kondisi fisik kantor seperti: penerangan, suhu udara, dll. Lingkungan kerja juga dapat berupa uraian jabatan yang jelas, wewenang yang memadai, target kerja yang menantang, pola komunikasi yang baik, hubungan kerja yang harmonis, iklim kerja yang dinamis, terdapat peluang karir, dan fasilitas kerja yang memadai. Jika lingkungan kerja tidak memuaskan karyawan, hal tersebut dapat menurunkan semangat kerja dan akhirnya menurunkan produktifitas kerja karyawan [7]. Displin adalah bentuk pengendalian diri karyawan yang dilaksanakan secara teratur sebagai bentuk kesungguhan karyawan dalam sebuah organisasi [8].

Structural Equation Modeling (SEM) adalah teknik analisis statistika yang mampu menganalisis pola hubungan variable laten dan indikatornya [4]. Structural Equation Modeling (SEM) digunakan untuk membangun dan menguji model statistik yang pada umumnya berbentuk model sebab akibat [9]. Structural Equation Modeling (SEM) memiliki kemampuan analisis dan prediksi yang lebih baik dari analisis jalur dan regresi berganda, hal itu disebabkan Structural Equation Modeling (SEM) mampu menganalisis hingga level terdalam terhadap variable/model yang diteliti [10].

Tujuan penelitian adalah untuk mengetahui pengaruh lingkungan kerja dan beban kerja terhadap kinerja karyawan Unit Pelayanan Terpadu Satu Pintu (UP PTSP) Kecamatan Makasar serta mengetahui faktor-faktornya yang harus di prioritaskan untuk menjadi lebih baik.

\section{METODE PENELITIAN}

Jenis penelitian yang digunakan adalah kuantitatif dengan menggunakan teknik cluster sampling. Metode untuk mengolah data dalam penelitian ini dengan menggunakan Structural Equation Modelling (SEM). Penelitian ini menggunakan beberapa metode dalam pengumpulan/pengambilan data yaitu data primer dan data skunder. Data primer diambil dengan survey serta membagikan kuesioner kepada responden, metode yang digunakan untuk pengolahan data primer adalah Structural Equation Modelling (SEM) dengan menggunakan software AMOS. Data skunder adalah data tidak langsung dari objek penelitian yang ada di Unit Pelayanan Terpadu Satu Pintu (UP PTSP) Kecamatan Makasar dan studi pustaka berupa jurnal yang berhubungan dengan penelitian. Responden pada penelitian ini adalah seluruh karyawan yang berada di Unit Pelayanan Terpadu Satu Pintu (UP PTSP) Kecamatan Makasar. Alat pengumpulan data yang digunakan adalah kuesioner penelitian dengan variabel eksogen lingkungan kerja (X1) dan beben kerja (X2) yang mempengaruhi variabel endogen yaitu kinerja karyawan (Y).

\section{HASIL DAN PEMBAHASAN}

Berikut ini adalah pengujian Structural Equation Modeling (SEM) secara full model. Pengujian hasil pengolahan data pada tahap full model Structural Equation Modeling (SEM) dilakukan dengan melakukan uji statistik. Hasil pengolahan data untuk pengujian full model Structural Equation Modeling (SEM) ditampilkan pada gambar dan tabel berikut. 


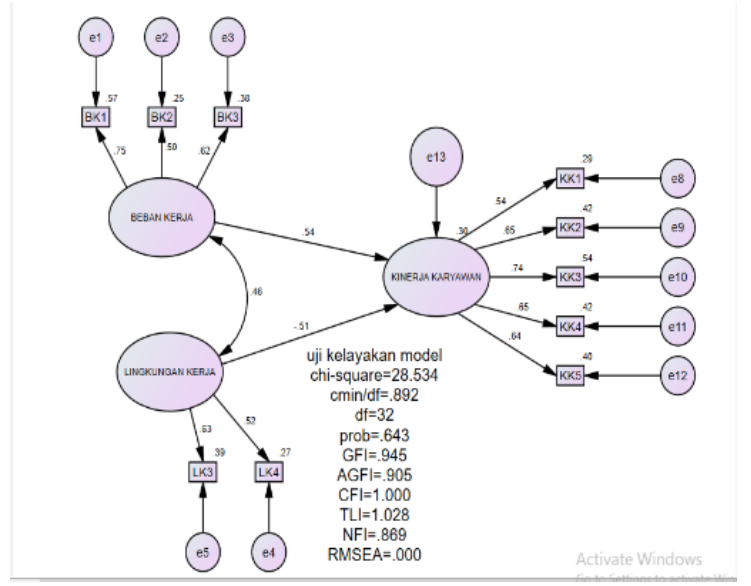

Gambar 1. Hasil pengujian Stuctural Equation Modelling (SEM)

Sumber: hasil perhitungan software AMOS

Uji terhadap kelayakan full model Structural Equation Modeling (SEM) ini diuji dengan menggunakan Chi-square, Goodness of Fit Indeks (GFI), Comparative Fit Index (CFI). Tucker Lewis Index (TLI), Adjusted Goodness Fit Of Index (AGFI), The Minimum Sample Discrepancy Function Devided with degrre of Freedom (CMIN/DF), dan Root Mean Square Error of Approximation (RMSEA) berada dalam rentang nilai yang diharapkan. Hasil pengujian kelayakan full model Structural Equation Modeling (SEM) dapat dilihat pada tabel 1.
Tabel 1. Hasil Pengujian Kelayakan Full Model (SEM)

\begin{tabular}{|c|c|c|c|c|}
\hline No & Kriteria & $\begin{array}{c}\text { Nilai } \\
\text { Rekomendasi }\end{array}$ & $\begin{array}{c}\text { Hasil } \\
\text { Model }\end{array}$ & Ket \\
\hline 1 & Chi-square & $\begin{array}{c}\text { Diharapkan } \\
\text { kecil X2 } \\
\text { dengan DF }=32\end{array}$ & 28.534 & Baik \\
\hline 2 & Probability & $\geq 0.05$ & 0.643 & Baik \\
\hline 3 & CMIN/DF & $\leq 2.00$ & 0.892 & Baik \\
\hline 4 & GFI & $\geq 0.90$ & 0.945 & Baik \\
\hline 5 & AGFI & $\geq 0.80$ & 0.905 & Baik \\
\hline 6 & TLI & $\geq 0.90$ & 1.028 & Baik \\
\hline 7 & CFI & $\geq 0.90$ & 1.000 & Baik \\
\hline 8 & RMSEA & $\leq 0.08$ & 0.000 & Baik \\
\hline
\end{tabular}

Hasil tersebut menunjukan bahwa model yang digunakan dapat diterima. Tingkat nilai Chi-square yang bernilai 28.534 menunjukan model yang baik. Probabilitas sebesar 0.643 menunjukan sebagai suatu model persamaan struktural yang baik. Indeks pengukuran Goodness Of Fit Indeks (GFI), Adjusted Goodness Fit Of Index (AGFI), Tucker Lewis Index (TLI), Comparative Fit Index (CFI), The Minimum Sample Discrepancy Function Devided with degrre of Freedom (CMIN/DF), dan Root Mean Square Error of Approximation (RMSEA) berada dalam rentang nilai yang diharapkan untuk data yang fit.

Pada pembahasan sebelumnya yaitu pengolahan data menggunakan metode Structural Equation Modelling (SEM) untuk mencari hubungan antar variabel dan seberapa besar pengaruh terhadap pengaruh indikator-indikator terhadap variabel peningkatan kinerja karyawan dapat dilihat pada tabel 2 . 
Tabel 2. Estimasi Parameter Model (SEM)

Regression Weights: (Group number 1 - Default model)

\begin{tabular}{|cc|ccccc|}
\hline & & Estimate & S.E. & C.R. & P & Label \\
\hline KK $<---$ & BK & .411 & .175 & 2.343 & .019 & par_8 \\
KK $<---~$ & LK & -.792 & .422 & -1.876 & .061 & par_9 \\
BK1 <--- & BK & 1.000 & & & & \\
BK2 <--- & BK & .487 & .145 & 3.351 & $* * *$ & par_1 \\
BK3 <--- & BK & .648 & .169 & 3.838 & $* * *$ & par_2 \\
LK4 <--- & LK & 1.000 & & & & \\
LK3 <--- & LK & 1.279 & .531 & 2.407 & .016 & par_3 \\
KK1 <--- & KK & 1.000 & & & & \\
KK2 <--- & KK & 1.131 & .261 & 4.340 & $* * *$ & par_4 \\
KK3 <--- & KK & 1.239 & .273 & 4.533 & $* * *$ & par_5 \\
KK4 <--- & KK & 1.082 & .244 & 4.429 & $* * *$ & par_6 \\
KK5 <--- & KK & 1.003 & .236 & 4.249 & $* * *$ & par_7 \\
\hline \multicolumn{7}{c}{ Sumber: hasil perhitungan software AMOS }
\end{tabular}

\section{Analisis Pengaruh Lingkungan Kerja terhadap Kinerja Karyawan}

Setelah secara keseluruhan sebuah struktur model dianggap fit dan dapat dikatakan hampir menyerupai kondisi sebenarnya. Proses selanjutnya adalah melihat hubungan yang signifikan dan erat antar variabel independen dengan variabel dependen pada sebuah struktur model. Sehubungan dengan hal tersebut maka hipotesis yang dirumuskan pada penelitian ini dapat dilihat untuk hipotesis pertama (T1), yaitu:

Ho : Tidak ada pengaruh signifikan antara Lingkungan kerja (X1) terhadap Kinerja Karyawan (Y).

H1 : Terdapat pengaruh signifikan antara Lingkungan Kerja (X1) terhadap Kinerja Karyawan (Y).

Untuk mengetahui nilai hubungan antar konstruk dapat dilihat berdasarkan nilai probability $(\mathrm{P})$ pada output AMOS seperti yang ditunjukan pada Tabel 4.8. Dasar dari pengambilan keputusan adalah sebagai berikut:

a. Jika $\mathrm{P}>0.05$ maka Ho diterima

b. Jika $\mathrm{P}<0.05$ maka Ho ditolak
Tabel 3. SEM Lingkungan Kerja Terhadap Kinerja Karyawan

\begin{tabular}{|c|c|c|c|c|c|c|}
\hline & & $\begin{array}{c}\text { Estim } \\
\text { ate }\end{array}$ & S.E. & C.R. & $\mathrm{P}$ & Label \\
\hline $\begin{array}{l}\text { Kinerja } \\
\text { Karyaw <- } \\
\text { an }\end{array}$ & $\begin{array}{l}\text { Ling } \\
\text { kung } \\
\text { an } \\
\text { Kerja }\end{array}$ & -.792 & $\begin{array}{c}.42 \\
2\end{array}$ & $1 . \overline{876}$ & $\begin{array}{c}.06 \\
1\end{array}$ & par_9 \\
\hline
\end{tabular}

Berdasarkan nilai $\mathrm{P}$ pada Tabel 3 dari output Structural Equation Modelling (SEM) yang menjelaskan hubungan antar konstruk menunjukan bahwa lingkungan kerja terhadap kinerja karyawan menghasilkan nilai $\mathrm{P}$ sebesar 0.061 , hal ini menunjukan nilai $\mathrm{P} 0.061>0.05$. Dengan demikian Ho diterima yang berarti tidak ada pengaruh signifikan antara lingkungan kerja terhadap kinerja karyawan.

\section{Analisis Pengaruh Beban Kerja terhadap Kinerja Karyawan \\ Pembahasan analisis selanjutnya adalah melihat hubungan yang signifikan dan erat antara beban kerja terhadap kinerja karyawan pada sebuah structural model. Sehubungan dengan hal tersebut maka hipotesis yang dirumuskan pada penelitian ini dapat dilihat untuk hipotesis kedua (T2), yaitu:}


$\mathrm{H}_{\mathrm{o}}$ : Tidak ada pengaruh secara signifikan antara Beban Kerja (X2) terhadap kinerja Karyawan (Y).

$\mathrm{H}_{1}$ : Terdapat pengaruh secara signifikan antara Beban Kerja (X2) terhadap kinerja Karyawan (Y).

Untuk mengetahui nilai hubungan antar beban kerja terhadap kinerja karyawan dapat dilihat berdasarkan nilai probability (P) pada output AMOS seperti yang ditunjukan pada Tabel 4.8. Dasar dari pengambilan keputusan adalah sebagai berikut:

1. Jika $\mathrm{P}>0.05$ maka $\mathrm{H}_{\mathrm{o}}$ diterima

2. Jika $\mathrm{P}<0.05$ maka $\mathrm{H}_{0}$ ditolak

Tabel 4. SEM Beban Kerja Terhadap Kinerja Karyawan

\begin{tabular}{|c|c|c|c|c|c|c|}
\hline \multirow[b]{2}{*}{$\begin{array}{l}\text { Kinerja } \\
\text { Karyau } \\
\text { an }\end{array}$} & \multirow[b]{2}{*}{$\begin{array}{l}\text { Beba } \\
n \\
\text { Kerja }\end{array}$} & $\begin{array}{l}\text { Esti } \\
\text { mat } \\
\mathrm{e}\end{array}$ & $\begin{array}{c}\text { S.E } \\
\text {. }\end{array}$ & C.R. & $\mathrm{P}$ & $\begin{array}{l}\text { Lab } \\
\text { el }\end{array}$ \\
\hline & & .411 & .175 & 2.343 & $\begin{array}{c}.01 \\
9\end{array}$ & par_8 \\
\hline
\end{tabular}

Sumber: hasil perhitungan software AMOS

Berdasarkan nilai $\mathrm{P}$ pada tabel 4 dari output Structural Equation Modelling (SEM) yang menjelaskan hubungan antar konstruk menunjukan bahwa beban kerja terhadap kinerja karyawan menghasilkan nilai $\mathrm{P}$ sebesar 0.019 yang berarti nilai $\mathrm{P}<$ 0.05. Dengan demikian Ho ditolak yang berarti ada pengaruh signifikan antara beban kerja terhadap kinerja karyawan.

\section{Analisis Pengaruh Indikator Lingkungan Kerja}

Setelah mengetahui hubungan antara lingkungan kerja terhadap kinerja karyawan yaitu tidak terdapat hubungan yang signifikan. Hal ini menunjukan juga bahwa indikator-indikator yang terdapat pada (LK1) lingkungan kerja seperti penerangan, (LK2) sirkulasi udara, (LK3) kebersihan, dan (LK4) tata warna tempat kerja [11] tidak akan mempengaruhi secara signifikan terhadap kinerja karyawan. Tetapi dalam hal lain, kita akan membahas mengenai pengaruh indikatorindikator lingkungan kerja manakah yang harus diprioritaskan dalam lingkungan kerja terhadap peningkatan kinerja karyawan. Dapat kita lihat berdasarkan output AMOS berikut ini.

Tabel 5. Regression Weight SEM Indikator Lingkungan Kerja

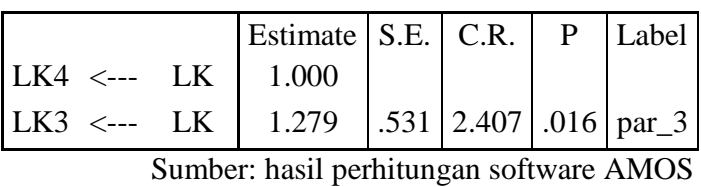

Berdasarkan Tabel 5, untuk melihat seberapa besar pengaruhnya yaitu dengan melihat nilai estimase terbesar yaitu pada indikator LK3 atau kebersihan di tempat kerja. LK1 dan LK2 tidak tercantum pada hasil output karena telah di estimate sebelumnya karena indikator tersebut tidak memiliki pengaruh signifikan terhadap lingkungan kerja. Dengan demikian yang harus diprioritaskan dalam meningkatkan lingkungan kerja yang lebih baik yaitu kebersihan ditempat kerja (LK3).

\section{Analisis Pengaruh Indikator Beban Kerja}

Setelah kita mengetahui indikator yang harus diprioritaskan dalam lingkungan kerja, kita juga harus membahas mengenai pengaruh indikator-indikator beban kerja yang mempengaruhi beban kerja terhadap peningkatan kinerja karyawan.

Sebelumnya telah didapatkan hasil analisis bahwa terdapat hubungan secara signifikan antara beban kerja terhadap kinerja karyawan. Hal ini menunjukan juga bahwa indikator-indikator yang terdapat pada beban kerja seperti (BK1) kondisi pekerjaan, (BK2) penggunaan waktu kerja, dan (BK3) target yang harus dicapai [11] akan mempengaruhi secara signifikan terhadap kinerja karyawan. 
Tetapi dalam hal lain, kita akan membahas mengenai pengaruh indikator beban kerja manakah yang harus diprioritaskan.

Tabel 6. Regression Weight SEM Indikator Beban Kerja

\begin{tabular}{|lll|ccccc|}
\hline BK1 & $<---$ & BK & Estimate & S.E. & C.R. & P & Label \\
BK2 & $<---$ & BK & .487 & .145 & 3.351 & $* * *$ & par_1 \\
BK3 & $<---$ & BK & .648 & .169 & 3.838 & $* * *$ & par_2 \\
\hline \multicolumn{5}{|c|}{ Sumber: hasil perhitungan software AMOS }
\end{tabular}

Berdasarkan tabel 6, untuk melihat seberapa besar pengaruhnya yaitu dengan melihat estimate dari output AMOS yang dihasilkan. Nilai estimate terbesar yaitu pada indikator BK1 atau kondisi pekerjaan. Dengan demikian indikator yang paling berpengaruh terhadap beban kerja adalah kondisi pekerjaan (BK1). Hal ini menunjukan bahwa kondisi yang dibuat perusahaan terlalu membuat beban pekerjaan yang besar. Sehingga dalam hal meningkatkan kinerja karyawan yang lebih baik, kondisi dalam pekerjaannya harus diseimbangkan sehingga kinerja karyawan bisa lebih baik lagi.

\section{Analisis Strategi Peningkatan Kinerja Karyawan}

Dari hasil penelitian yang sudah dilakukan bahwa kondisi lingkungan kerja tidak ada pengaruh yang signifikan terhadap kinerja karyawan tetapi prioritas utama dalam meningkatkan kinerja karyawan melalui lingkungan kerja adalah menjaga kebersihan di tempat kerja. Untuk itu dalam peningkatan kinerja karyawan ditempat kerja harus dijaga dengan membuang sampah pada tempatnya, membersihkan meja kerja pada saat selesai kerja, menata dokumen sesuai dengan tempat penyimpanannya, dan merapikan tempat pelayananan masyarakat supaya masyarakat merasa nyaman dengan kondisi ruangan yang nyaman dan bersih.

Sedangkan untuk beban kerja ada pengaruh yang signifikan terhadap kinerja karyawan dalam peningkatan kinerja terutama kondisi pekerjaan. Untuk itu dalam peningkatan kinerja karyawan diperlukan pekerjaan yang sesuai dengan tugas pokok dan fungsi setiap bagian pekerjaan, hal ini dapat mempengaruhi beban kerja pada karyawan sehingga tidak mudah stress dan sakit yang menyebabkan tingkat kehadiran menurun dan sering meninggalkan pekerjaan.

\section{SIMPULAN}

Berdasarkan nilai output regression weights SEM lingkungan kerja (X1) terhadap kinerja karyawan (Y) menghasilkan nilai $\mathrm{P}$ sebesar $0.061, \mathrm{H}_{0}$ diterima yang berarti tidak ada pengaruh yang signifikan antara lingkungan kerja terhadap kinerja karyawan. Sedangkan beban kerja (X2) terhadap kinerja karyawan (Y) menghasilkan nilai P sebesar $0.019, \quad \mathrm{H}_{0}$ di tolak yang berarti ada pengaruh yang signifikan antara beban kerja terhadap kinerja karyawan. Prioritas utama dalam meningkatkan kinerja karyawan melalui lingkungan kerja yaitu dengan kebersihan di tempat kerja. Prioritas utama dalam meningkatkan kinerja karyawan melalui beban kerja yang lebih baik yaitu dengan kondisi pekerjaan di tempat kerja.

\section{DAFTAR PUSTAKA}

[1] A. Hakim, "Model Peningkatan Kinerja Karyawan Melalui Peran Komunikasi dan Motivasi Serta Pengaruhnya Terhadap Kepuasan Kerja," EKOBIS, vol. 15, no. 2, pp. 1-18, 2014.

[2] A. Bianca, P. B. Katili, and S. K. Anggraeni, "Pengaruh Motivasi, Pengembangan Karir, dan Kepuasan Kerja Terhadap Kinerja Karyawan dengan Metode Structural Equation Modelling," J. Tek. Ind., vol. 1, no. 4, pp. 334-340, 2013.

[3] E. D. Supandia and S. Mutmainatus $\mathrm{S}$, "Pengaruh Remunerasi dan 
Motivasi terhadap Kinerja Pegawai UIN Sunan Kalijaga dengan SEM," in PRISMA, Prosiding Seminar Nasional Matematika, 2020, vol. 3, pp. 84-94.

[4] A. Wibisono, M. Anwar, and I. Kirono, "Stuctural Equation Modeling Partial Least Square (SEM PLS) Untuk Mengetahui Kinerja Karyawan Pada PT. Dempo Laser Metalindo Surabaya," J Stat., vol. 7, pp. 15-24, 2015.

[5] W. E. Susetyo, A. Kusmaningtyas, and $\mathrm{H}$. Tjahjono, "Pengaruh Budaya Organisasi dan Lingkungan Kerja Terhadap Kepuasan Kerja dan Kinerja Karyawan Pada PT Bank Muamalat Indonesia Divisi Konsumer Area Cabang Surabaya," J. Ilmu Ekon. Manaj., vol. 1, no. 1, pp. 83-93, 2014.

[6] S. Haryono and Y. Pamungkas, "Pengaruh Kualitas Kehidupan Kerja Terhadap Kinerja Dengan Kepuasan dan Disiplin Kerja Sebagai Variabel Intervening," $J$. Manaj. dan Perbank., vol. 4, no. 1, pp. 1-23, 2017.

[7] A. A. N. B. Dhermawan, I. G. A. Sudibya, and I. W. M. Utama, "Pengaruh Motivasi, Lingkungan Kerja, Kompetensi, dan Kompensasi Terhadap Kepuasan Kerja dan Kinerja Pegawai Di Lingkungan Kantor Dinas Pekerjaan Umum Provinsi Bali," J. Manajemen, Strateg. Bisnis, dan Kewirausahaan, vol. 6, no. 2, pp. 173-184, 2012.
[8] Lianasari, P. Wardoyo, and D. Santoso, "Pengaruh Stres Kerja, Employee Engagment, dan Kedisiplinan Terhadap Kinerja Dengan Kepuasan Kerja Sebagai Variabel Intervening Pada Karyawan CV Karya Manunggal Semarang," Neo-Bis, vol. 11, no. 2, pp. 172-197, 2017.

[9] B. Wirawan D S, "Analisis Hubungan Antara Kepuasan Kerja Dan Kinerja Karyawan Dengan Structural Equation Modeling (SEM): Studi Kasus Di PT Yamaha Music MFG Asia," in Seminar Nasional Strategi Pengembangan Sumber Daya Manusia Melalui Publikasi Jurnal Ilmiah dalam Menyikapi Permenristekdikti RI No.20 Tahun 2017, 2017, pp. 270 279.

[10] R. N. Meilita, Y. N. Nasution, and M. N. Hayati, "Structural Equation Modelling Dengan Pendekatan Partial Least Square (Studi Kasus: Pengaruh Locus of Control, Self Efficacy, dan Lingkungan Kerja Terhadap Kinerja Karyawan Kaltim Post Samarinda)," in Prosiding Seminar Sains dan Teknologi FMIPA Unmul, 2016, vol. 1, no. 1, pp. 41-45.

[11] Romadhan, Bahri Jannah. 2017. "Usulan Peningkatan Kinerja Karyawan Pada PT. Media Karya Sentosa Dengan Metode Structural Equation Modelling (SEM)". Skripsi. Program Studi Teknik Industri Fakultas Teknik Dan Ilmu Komputer Universitas Indraprasta PGRI. 